East African Medical Journal Vol. 77 No. 6 June 2000

PREVALENCE OF RISK FACTORS FOR TRACHOMA IN A RURAL LOCALITY OF NORTH-WESTERN ETHIOPIA

G.D.Alene, B.Sc., M.Sc. Lecturer, Gondar College of Medical Sciences, P.O. Box 196, Gondar, Ethiopia and S. Abebe, B.Sc., Head, Bahar Dar Zonal Health Department, P.O. Box 1159, Bahar Dar, Ethiopia.

Request for reprints to: G. D. Alene, Gondar College of Medical Sciences, P.O. Box 196, Gondar, Ethiopia.

\title{
PREVALENCE OF RISK FACTORS FOR TRACHOMA IN A RURAL LOCALITY OF NORTH- WESTERN ETHIOPIA
}

\author{
G.D.ALENE and S. ABEBE
}

\begin{abstract}
Background: In Ethiopia, the prevalence of blindness has been estimated to be $1.5 \%$. According to a survey done in collaboration with WHO in 1981, the leading cause of blindness in Ethiopia was trachoma $(42 \%)$ followed by cataract $(29 \%)$. The problem is mainly seen in the rural areas of the country.

Objective: To determine the prevalence and associated risk factors of trachoma in a rural locality of north-western Ethiopia.

Design: Cross-sectional survey.

Subjects: One thousand seven hundred and eighteen individuals participated in the study. Main outcome measures. Grades of trachoma - the WHO simplified method of clinical signs was used to determine the various grades of trachoma.

Results: The overall prevalence rate of trachoma of the locality was $59.2 \%$ while the prevalence rate of active trachoma was found to be $52.4 \%$. Higher frequency of trachoma was observed among females aged 15 years and above than males of the corresponding age group, and this finding was statistically significant $(\chi 2$-test, $\mathbf{p}<0.001)$. Child care-taking among women, habits and frequency of face washing, presence of cooking places in living rooms and sharing of same rooms with animals have been found to be highly associated with trachoma $(\mathbf{p}<0.001)$.

Conclusion: Based on the results of this study, the following recommendations are made, among others: (i) the development of a system aimed at educating and convincing the people to maintain high personal and environmental hygiene and; (ii) the strengthening of the nearby health centres to incorporate activities like correction of lid deformities to prevent further loss of eye vision due to corneal damage are recommended.
\end{abstract}

\section{INTRODUCTION}

The word "trachoma", was first used in Graeco Roman times. It comes from the Greek word "rough" which describes the surface appearances of the conjunctiva in chronic trachoma(1). It is a form of kerato-conjunctivitis which is communicable and usually of chronic evaluation. Its causative agent Chlamydia trachomatis is spread by direct contact, dirt and flies. The distribution over the eye ranges from conjunctivitis often follicular to most disabling forms of entropion and trichiasis formation, corneal scarring, complete corneal opacity and blindness(1).

Trachoma is the greatest single cause of preventable blindness worldwide(1). According to a study carried out in 1997, there were 38 million blind people and almost 110 million with low vision, giving a total of nearly 150 million people with some degree of visual impairment (2). Trachoma is a disease of developing countries where the standard of living is low(3). More than $90 \%$ of the global burden of blindness is found in the developing countries and the vast majority of the problem is seen in the rural areas of these countries(3).
In Africa, the prevalence of blindness is estimated to be $1.2 \%$ of the population with variation between $0.3 \%$ and $4.7 \%$ (3). In Ethiopia, the prevalence of blindness has been estimated to be $1.5 \%$. According to a survey done in collaboration with WHO in 1981, the leading cause of blindness in Ethiopia was trachoma (42\%) followed by cataract (29\%). Among the current estimated 825,000 blind people in this country, 346,500 lost their vision due to trachoma(4-7).

Blindness, apart from the stigma it brings on the individual, has a profound socio-economic impact on the development of a given country. Rehabilitation and education of the blind constitutes significant economic burden particularly among many developing countries like Ethiopia. Furthermore, blindness is often associated with lower life expectancy in such settings. Therefore, to prevent blindness from trachoma, much emphasis should be given towards reaching and treating cases of trachoma and the design of control strategies in areas where it is prevalent, particularly in the remote rural areas. However, to do so, the need for adequate information on the magnitude and distribution of the disease and the associated risk 
factors in such remote areas is beyond doubt, hence the design of this study.

\section{MATERIALS AND METHODS}

A cross-sectional study to determine the prevalence and associated risk factors of trachoma was conducted in a rural locality called Jangua Mariam, North Western Ethiopia, from October to December 1998.

Jangua Mariam is found in the district of Dembia some 45 kms away from the city of Gondar which is the capital of North Gondar Administrative Zone. Jangua Mariam is a big locality which consists of three rural villages. The city of Gondar is located at a distance of $750 \mathrm{kms}$ from Addis Ababa.

After repeated discussions with the authorities of the district, a formal letter was sent to the local leaders of Jangua Mariam for the necessary support that would be given during data collection. Accordingly, numbering of the houses, mapping of the entire locality, collection of the required data and other related activities were done with the kind assistance of these local leaders. The total number of houses numbered and the total population registered were 414 and 1864 respectively. All individuals of all age groups residing in the locality were eligible for the study.

All the 414 households were included in the study and the required data were collected from $1718(92.2 \%)$ of the entire population of the locality. That is, some 146 individuals living in some of the households were not present at the time of the survey accounting for a non-response rate of $7.8 \%$. However, some members of the households to which these absentees belonged were included in our study.

Four Health Officer final-year students were involved in the data collection. An intensive one week training about examination of the eye and collection of the required information was given to the data collectors by an ophthalmologist of the Gondar College of Medical Sciences (GCMS) and the coordinators of the project. At the end of training the Health Officers were able to correctly identify the stages of trachoma.

The survey was done by doing clinical examinations on both eyes for each person of the entire population of the locality during daylight. Study participants were instructed to sit face to face with the examiner keeping their heads up but looking down to facilitate easy evertion of the eye lid. Both eyes were examined in the same way using a magnification convergent $2.5-3.5$ times binocular loups adjustable to the pupillary distance of the observer. The final finding of the eye examination was recorded on a format prepared for that purpose.

The WHO simplified method of clinical signs was used to determine the grades of trachoma and the result of each diagnosis was graded as follows:

$\mathrm{TO}=$ no visible sign of trachoma infection.

$\mathrm{TF}=$ trachomatous follicles - the presence of five or more follicles in the upper tarsal conjunctiva.

$\mathrm{TI}=$ trachomatous intense inflammation pronounced inflammatory thickening of the tarsal conjunctiva that obscures more than half of the normal deep tarsal vessel.

$\mathrm{TS}=$ follicles with visible scarring on the inside of the eye lids. $\mathrm{TT}=$ trachomatous trichiasis - at least one eye lash rubbing the eye, or recent evidence of removal of inturned eye lashes.

$\mathrm{CO}=$ corneal opacity - easily visible corneal opacity over the pupil.

The eye examination of each individual was performed by two examiners separately and whenever a difference in the finding of the diagnosis appeared, a third examiner would verify the examination. Identical findings of the two examiners were taken as the final result. There were also few occasions where the fourth examiner would carry out the same investigation in order to arrive at a final decision. In that situation, diagnosis results agreed upon by at least three examiners would be taken as the final ones.

A questionnaire which was pre-tested on 20 households of a nearby area was used to collect the information on demographic and socio-economic variables. In addition to the grades of trachoma, information on variables like age, sex, previous eye problem, frequency and face washing habits, waste disposal and latrine facilities, sharing of same room with animals, cooking place in the same room, were collected.

Data entry, compilations and analyses were carried out using EPI-INFO version 5 software package. Descriptive statistics and Chi-square statistical tests were applied and p-values less than 0.05 were considered significant.

\section{RESULTS}

A total of $414(100 \%)$ householdswere surveyed during the census and examination of the eye was performed on $1718(92.2 \%)$ of the residents of the study area. The total number of males examined was $842(49 \%)$ while the remaining $876(51 \%)$ were females. Almost all (99.9\%) residents of the study area were Orthodox Christians. Of the total population examined, subsistence farmers, housewives, students and shepherds constituted $26.6 \%$, $21.1 \%, 12.3 \%$ and $10.6 \%$ respectively. Children below seven years of age who were not economically active were found to be $27.3 \%$ and others like priests, monks and unemployed people, constituted the remaining $2.1 \%$.

Among the total number of persons examined, 1017 $(59.2 \%)$ had trachoma (all stages). When these cases of trachoma were investigated according to age, it was found out that the age group 5 to 9 years accounted for the highest prevalence $(74.6 \%)$. As can be seen from Table 1, the prevalence of trachoma varied from $49 \%$ for age group 10 - 14 years to $74.6 \%$ for children between five and nine years.

Active trachoma was present in 901 (52.4\%) of all persons examined. It was also observed from this study that $30(1.75 \%)$ of the cases required lid surgery for trichiasis. The distribution of trachoma cases by type of grade and sex is shown in Table 2.

During the survey it was found out that $100 \%$ of the households in the study area did not have latrine and waste disposal facilities. The water source of the households was far and $68.6 \%$ of them had to travel more than one hour while $23.1 \%$ had to spend about 30 minutes to fetch water. It was also observed that only $8.3 \%$ were able to fetch water in 15 minutes. As far as water consumption was concerned, the great majority of the households (93\%) consumed $<12$ litres per day while only $7 \%$ of the total households were able to use 12 and above litres of water for all water consuming activities of the household. The study also revealed that the two main water sources for the 414 households were river water $(92.5 \%)$ and unprotected spring water $(7.5 \%)$. 
Table 1

Distribution of trachoma cases by age group and sex

\begin{tabular}{|c|c|c|c|c|c|c|c|c|c|}
\hline \multirow[t]{2}{*}{ Age in years } & \multirow[b]{2}{*}{ M } & \multirow[b]{2}{*}{ F } & \multirow[b]{2}{*}{ Total } & \multicolumn{2}{|c|}{$\begin{array}{l}\text { Number of positive } \\
\text { Number examined }\end{array}$} & \multicolumn{4}{|c|}{$\begin{array}{c}\text { Percent }(\%) \text { of } \\
\text { cases positive cases }\end{array}$} \\
\hline & & & & M & $\mathrm{F}$ & Total & M & $\mathrm{F}$ & Total \\
\hline $0-4$ & 146 & 138 & 284 & 89 & 78 & 167 & 61.0 & 56.5 & 58.8 \\
\hline 5- 9 & 151 & 152 & 303 & 108 & 118 & 226 & 71.5 & 77.6 & 74.6 \\
\hline $10-14$ & 118 & 131 & 249 & 52 & 70 & 122 & 44.1 & 53.4 & 49.0 \\
\hline $15+$ & 427 & 455 & 882 & 191 & 311 & 502 & 44.7 & 68.4 & 56.9 \\
\hline Total & 842 & 876 & 1718 & 440 & 577 & 1017 & 52.3 & 65.9 & 59.2 \\
\hline
\end{tabular}

$\mathrm{M}=$ Male

$\mathrm{F}=$ Female

Table 2

Distribution of trachoma cases by grades of trachoma

\begin{tabular}{|c|c|c|c|c|c|c|}
\hline \multirow{2}{*}{$\begin{array}{l}\text { Trachoma } \\
\text { grade }\end{array}$} & \multicolumn{2}{|c|}{ Male } & \multicolumn{2}{|c|}{ Female } & \multicolumn{2}{|c|}{ Total } \\
\hline & Number & $\%$ & Number & $\%$ & Number & $\%$ \\
\hline TF & 351 & 79.8 & 498 & 86.3 & 849 & 83.5 \\
\hline TI & 22 & 5.0 & 30 & 5.2 & 52 & 5.1 \\
\hline TS & 47 & 10.7 & 25 & 4.3 & 72 & 8.5 \\
\hline TT & 14 & 3.2 & 16 & 2.8 & 30 & 2.9 \\
\hline $\mathrm{CO}$ & 6 & 1.3 & 8 & 1.4 & 14 & 1.4 \\
\hline Total & 440 & 100 & 577 & 100 & 1017 & 100 \\
\hline
\end{tabular}

Table 3

Influence of demographic and socio-economic characteristics on trachoma

\begin{tabular}{|c|c|c|c|c|c|}
\hline \multirow{2}{*}{\multicolumn{2}{|c|}{ Characteristic (factor) }} & \multicolumn{2}{|c|}{ Trachoma } & \multirow[t]{3}{*}{ OR } & \multirow[t]{3}{*}{ P-value } \\
\hline & & Present & Absent & & \\
\hline & Female (all age groups) & 577 & 299 & & \\
\hline & Male (all age groups) & 440 & 402 & 1.76 & $<.0001$ \\
\hline \multirow[t]{2}{*}{ Sex } & Female $(<15$ years $)$ & 266 & 155 & & \\
\hline & Male (<15 years $)$ & 249 & 166 & 1.14 & $>.30$ \\
\hline \multirow[t]{2}{*}{ Sex } & Female $(\geq 15$ years $)$ & 311 & 144 & & \\
\hline & Male ( $\geq 15$ years $)$ & 191 & 236 & 2.67 & $<.0001$ \\
\hline \multicolumn{6}{|c|}{ Face washing habit } \\
\hline & $\leq 1 /$ day & 1001 & 669 & 2.99 & $<.001$ \\
\hline & $>1 /$ day & 16 & 32 & & \\
\hline \multicolumn{6}{|c|}{ Cooking place in living room } \\
\hline & Yes & 989 & 655 & 2.48 & $<.001$ \\
\hline & No & 28 & 46 & & \\
\hline \multicolumn{6}{|c|}{ People sharing same room with animals } \\
\hline & Yes & 997 & 648 & & \\
\hline & No & 20 & 53 & 4.08 & $<.0001$ \\
\hline \multicolumn{6}{|c|}{ Child care-taking } \\
\hline & Caretakers & $\mathrm{I} 52$ & 73 & 2.99 & $<.0001$ \\
\hline & Non caretakers & 83 & 119 & & \\
\hline
\end{tabular}


The association of a number of variables with the presence of trachoma of all grades was investigated. As shown in Table 3, variables like sex (particularly in adults), face washing habit, cooking place in living room, people sharing rooms with animals and child care-taking were found to be significantly associated with trachoma ( $\chi 2$ - test, $p$-values were <.001 for each factor).

Females were at a higher risk of acquiring trachoma with an odds ratio of 1.76 ; $95 \%$ CI $(1.44-2.15)$ than males. The sex related prevalence of trachoma was further investigated for the inhabitants below 15 years old and for those aged 15 and above. Accordingly, the prevalence rates of trachoma among males and females of ages below 15 were $60 \%$ and $63.2 \%$ respectively. This difference was not statistically significant $(p>0.3)$. However, the comparison made between females and males of ages 15 years and above showed a statistically significant difference $(p<0.0001$, Table 3$)$. Individuals who had the habit of washing their faces at most once per day were almost three times at a higher risk of acquiring trachoma than those who washed their faces more than once per day. Similarly, mothers aged 15 to 60 who were found to be care-takers of children $<7$ years versus those who were non caretakers of children of the same age were investigated to determine their association with active trachoma. It was found out that the prevalence of active trachoma $(\mathrm{TF}+\mathrm{TI})$ among the care takers was $67.6 \%$ while it was $41.1 \%$ among the non care takers and the difference was statistically significant $(\chi 2$ - test, $\mathrm{p}<0.001)$.

\section{DISCUSSION}

The prevalence rates of trachoma in general and active trachoma in particular in the study area were found to be $59.2 \%$ and $52.4 \%$ respectively. This indicates that trachoma is a major health problem in this rural community. This might be attributed to poor personal hygiene and poor environmental sanitation, which favour transmission of the disease. This finding is in keeping with the result of a previous community-based study which was conducted in Ethiopia in 1988. That study which consisted of 18 small towns and 46 localities showed an overall trachoma prevalence rate of $58.7 \%(4,8)$.

The highest prevalence rate of trachoma was observed in the age group five to nine years (74.6\%). This could probably be due to the fact that children of this age group are highly exposed to dust and other risk factors while playing in open fields which may not be clean. The prevalence rates below 15 years and those aged 15 and above were also observed to be $61.6 \%$ and $56.9 \%$ respectively. The previous findings show that young children are highly affected by the disease. It is to be recalled that children are the reservoir of the causative organism Chlamydia trachomatis.

In this study, a higher prevalence rate of trachoma was observed in females $(65.9 \%)$ than in males $(52.3 \%)$ and the difference was found to be highly statistically significant $(\mathrm{p}<.0001)$. The comparison made between the prevalence rates of trachoma of females and males of ages below 15 years showed a non significant difference ( $p>0.3$ ). This could probably be due to the fact that males and females of ages below 15 are more or less equally exposed to the risk factors of trachoma. However, a similar comparison made for adults (15 and above) indicated that females were 2.67 times at a higher risk of acquiring the disease than males of the same age group ( $p$ <.0001). This could be due to the frequent close contact that women had with small children who are mostly affected with the infectious form of the disease. The reason why females in general (all age groups) were found to be at a higher risk of acquiring the disease than the males could be because of these highly exposed women who are large in numbers. Moreover, in a rural setting like Jangua Mariam, women are more exposed to irritants like smoke and dust(9). This fact was further investigated by considering women aged 15 to 60 years who were child caretakers and non caretakers. The increased prevalence rate of trachoma in women who were taking care of children below seven years versus non caretakers could be attributed to the day and night close contact with children who are the reservoir of the disease (Table 3).

Many studies done elsewhere have shown that the prevalence of trachoma is lower in individuals with the habit of face washing than those who do not have such practices $(3,7,10,11)$. Likewise, a similar finding was observed in this study. Those individuals who had the habit of washing their faces more than once per day were observed to be at a lower risk of acquiring the disease than those who did not have that practice. Lack of adequate and safe water in the study area, as indicated in the results section of this paper, might have negatively affected the majority of the population from developing the habit of washing their faces very frequently which subsequently resulted in a higher prevalence of trachoma among them.

The presence of cooking places in living rooms and sharing of these same rooms with animals in more than $95 \%$ of the households of the study area might have also aggravated the problem. The occurrence of $1.75 \%$ trichiasis and $0.8 \%$ corneal opacity indicate that trachoma is hyperendemic in this community(6). This situation of chronic trachoma coupled with a very high prevalence of active trachoma clearly indicate that there is blinding trachoma in that community which calls for immediate curative and preventive measures. In general, the problem of the disease is expected to be even more serious as we go further to the more non accessible remote rural communities. It is also interesting to note here that the prevalence of the disease as indicated in this study, did not show any difference from what it was in the last ten years(8).

Great efforts were made to minimise the number of non-respondents in the study area by making repeated visits and finally only $7.8 \%$ of the inhabitants of the community were not included in the study. This could probably be due to the fact that the survey was done during the harvesting season and both females and males of active 
age groups might not have been found at their homes. However, at least one individual was included in the study from each of the households which these absentees belonged. There is a strong feeling that the subjects included in the study would represent the population of the study area (Jangua Mariam) in particular and the great majority of the inhabitants of the district with similar topography and socio-economic characteristics. On the basis of the findings of this study, the following recommendations could be made: (i) mechanisms should be developed to make the population accessible to safe and adequate water which will also reduce the burden of women who are supposed to fetch water by covering long distances. This in turn will increase the productivity of the population as a whole; (ii) health education in connection with community-based activities should be given to improve personal and environmental hygiene stressing on the importance of clean faces to avoid transmission of the disease through eye seeking flies. Encouraging the communities to have latrine and waste disposal facilities from the available local materials should be emphasised and; (iii) the health centre responsible for the health of the communities should be able to perform surgical correction of lid deformities to prevent loss of vision due to corneal damage. This could be achieved by liaising with the Gondar College of Medical Sciences.

\section{ACKNOWLEDGEMENTS}

To the people of Jangua Mariam for consenting and participating in our study. To the authorities of the District of Dembia for all the necessary arrangements and support they gave us during data collection. Senior Health Officer students namely, Geletaw Ayalew, Tsehay Mesfin and Tesfaye G. Egziabher who participated in the data collection are highly acknowledged. We would like to express our appreciation to the members of the Department of Ophthalmology (GCMS) for their assistance in giving an intensive training to the data collectors. Our thanks also go to the GCMS for facilitating the study and provision of logistic support. Finally, we thank Dr. Workayehu Kebede, the Ophthalmologist of the GCMS, for his constructive comments and suggestions on the draft of article.

\section{REFERENCES}

1 Sandford-Smith, J. Eye disease in hot climate, 2nd edn,. Butterworth-Heinemann Ltd. Linacre House, Jordan Hill, Oxford: OX2 8DP: pp 78-79, 1990.

2. Bulletin of WHO. Global initiation for elimination of avoidable blindness: WHO/Pb1/97.6/ Rev.1, Geneva, 1997: 1-3.

3. Suka, T.Y., Mwandu, D.H. and Negalande, T.C. Prevalence of blindness and visual impairement in the Luapual Valley, Zambia. Trop. geogr. Med. J. 1988; 27 - 40.

4. Adamu L., Woldesadk M., and Almaz T. Guidelines for prevention of blindness in Ethiopia: Publication of Ministry of Health Programme for prevention of blindness, Addis Ababa 1998; pp 1 - 5.

5. Ministry of Health of Ethiopia. Guidelines for prevention of blindness in Ethiopia: Publication of Ministry of Health for Programme for prevention of blindness, Addis Ababa, 1996: pp $1-2$.

6. Hang-werners K., and Wolf-Deiter S. Trachoma frequency and treatment in the Gondar region. Ethiop. Med. J. 1987; 25: 5556.

7. Zein A.Z. and Helmut K. The Ecology of Health and Disease in Ethiopia: The blinding disease. Ministry of Health, Addis Ababa, 1988: 281-285.

8. Richard M. Rates of blindness in Ethiopia. Ethiop. Med. J. 1988; 26: 111-114.

9. Schwab L., R.Jr., Whitfield D., Ross-Degnan steinkuller P. and Swartwood J. The epidemiology of trachoma in rural Kenya: variation in prevalence with lifestyle and environment. The international Eye foundation, Bethesda, M.D. Mar. 1995; 102:475-82..

10. West, S., Munoz B., Lynch M., Kayongoya A., Chilangwa Z., Mmbaga B.B. and Taylor H.R. Impact of face washing on trachoma in Kongwa, Tanzania. Lancet. 1995; 345: 155-8.

11. Lynch M., West S., Munoz B., Kayongoya A., Taylor H.R. and Mmbaga B.B.Testing a participatory strategy to change hygiene behaviour: face washing in central Tanzania. Trans. roy. Soc. trop. Med. Hyg. 1994; 88: 513-7. 